\title{
MEMÓRIA E IDENTIDADE EM MARAJÓ, DE DALCÍDIO JURANDIR
}

RESUMO:

Este trabalho focaliza o processo de rememoração por meio da articulação entre diferentes instâncias temporais, que corresponde à apropriação da reminiscência no momento em que ela relampeja no presente. As associações, desencadeadas com base no processo da memória, trazem espaços e tempos diferentes.

PALAVRAS-CHAVE: narrativa, espaço, tempo, memória.

\begin{abstract}
Os seres humanos tendem a perceber o espaço em que vivem como centro do mundo. 0 homem perde atributos humanos na medida em que se distancia desse centro. A ilusão da centralidade é necessária à manutenção da cultura. 0 centro é, antes de mais nada, o Princípio, o lugar da mais concentrada das energias.
\end{abstract}

Antônio Sérgio Bueno, Vísceras da Memória.

Publicado somente em 1947 - embora concluído em 1939 -, o romance Marajó reúne dados, locais, fatos e acontecimentos identificáveis por quem conhece a região da Ilha do Marajó. Nesta obra, em particular, o discurso literário de Dalcídio Jurandir revela o domínio de um narrador sobre o assunto e sobre o ambiente narrado. Se, por um lado, o romance singulariza as histórias de alguns personagens; por outro, revela a voz de narradores anônimos que representam a memória coletiva da Ilha do Marajó. Em Marajó, o artifício literário possibilita um percurso por territórios da memória coletiva e individual, numa conexão entre passado e presente, recriando, no espaço da ficção, relações que remetem a elementos sociais, etnográficos, geográficos e antropológicos.

Contextualizado historicamente no início do século XX, o romance Marajó narra várias histórias que acontecem dentro e fora da grande Ilha do Marajó, na * Mestre em Letras: Estudos Literários (Área de concentração: Teoria da Literatura), 2001. 


\section{EM TESE}

Belo Horizonte, v. 6, p. I-253, ago. 2003

região Norte do Brasil. Tomando como cenário a imaginária fazenda Paricatuba, o narrador focaliza vários episódios, em torno de dois personagens: o coronel Coutinho, rico proprietário de terras na ilha, casado com D. Branca, e seu filho Missunga. Nas terras da fazenda, vivem os empregados - vaqueiros, cozinheiras, lavadeiras, amasde-leite. Entre as mulheres, estão as comadres do casal. Com elas, o coronel tem muitos filhos e filhas. Somente Missunga tem os privilégios de único herdeiro do poderoso coronel. Ao atingir a idade escolar, Missunga vai estudar na capital. A identidade, as relações de poder e a memória são apresentadas a partir do retorno do personagem Missunga, à Ilha do Marajó. Do entrelaçamento das reminiscências dos personagens surge a trama do romance.

No contexto da rememoração, o processo memorialístico se dá através da superposição de fases da vida do sujeito que rememora, em diferentes níveis indicadores de que a memória individual se acha associada à memória coletiva. A história de Missunga representa a história conjunta de um grupo social cujos componentes participam com recortes de lembranças que, aos poucos, vão desenhando o mapa cultural do espaço geográfico de Marajó. No romance, mesclam-se o local e a memória. No ponto de articulação entre esses dois aspectos, está a figura de Missunga.

Através dos deslocamentos do personagem Missunga, o narrador dá conta do processo de construção de um "fazendeiro Coronel" e de um "Coronel fazendeiro" registrando como os filhos dos fazendeiros se fazem doutores à custa de gado alheio. Após a morte do coronel Coutinho, torna-se evidente a morte de Missunga/filho, que se transforma imediatamente em coronel. A narrativa acompanha o jovem herdeiro, agora tratado pelo narrador como Manoel Coutinho.

À medida que a narrativa se aproxima do desfecho final, o olhar do narrador tenta criar em torno de Missunga uma "cortina protetora", capaz de livrá10 do destino que The está reservado por herança: Pai e tio só distinguiam a carne das vacas das carnes das mulheres porque as vacas valiam mais no matadouro. Ao pai e ao tio sua vida pertencia, era parte do latifúndio, o rebanho the seria entregue como herança.

0 novo Coutinho reencarnava as maldades do pai. Coronel Coutinho havia conseguido fazer de Missunga o seu legítimo herdeiro. 0 rapaz copiava toda a 
"pessimidade" dos brancos. 0 Dr. Manuel Coutinho tornara-se o dono até da água do rio Abai, que, a partir do "novo reinado", foi interditado para a pesca, destinandose ao uso exclusivo das manadas como bebedouro: a água do Abaí era para os bois beberem. 0 novo Coronel, como pai, era também o dono de tudo: dono daqueles campos imensos, dono das malhadas, dono dos jacarés, das marrecas, das onças, das cascavéis, dos tracajás. 0 garoto Missunga deu lugar ao fazendeiro opulento como fora seu pai, Coronel Coutinho.

Para configurar o ambiente da fazenda Paricatuba, no espaço da memória, o narrador concede voz a Missunga que, no presente da enunciação, evoca suas lembranças de infância, numa tentativa de reencontrar o menino que foi um dia. Tem início o processo rememorativo entre dois tempos distintos, vividos pelo mesmo sujeito que enfrenta, agora, o retorno brusco ao ambiente deixado para trás, quando ainda criança.

No contexto sócio-cultural focalizado até o momento, desdobra-se o processo memorialístico, um encontro entre o ontem, o hoje e o agora de quem se vê diante de suas próprias lembranças, tentando apreendê-las e refazê-las. Antonio Sérgio Bueno considera que, para realizar essa tarefa, o memorialista recorre a todos os seus sentidos, que passam a funcionar como "antenas poderosas nessas memórias e, entre eles, a visão e o tato". (Bueno, 1997: 83) Aos poucos, seres, objetos, cheiros e ruídos sobrepostos, proporcionam um reencontro entre o menino do passado e o adulto do presente para dar início à narrativa de Marajó.

Através da reconstituição do espaço familiar da infância, o personagem busca vencer o tédio, "as sensações da morte, de culpa iminente, do amor físico, do medo, da inércia, do estranho desalento e da extrema passividade diante do pai" (Jurandir, 1947: 10), no presente da enunciação. Entregue a essa atitude de abandono e inércia que envolve o presente, recorre aos sentidos, privando-se de um deles a visão -, para melhor fixar as imagens do passado:

De olhos fechados, muito bom ouvir sá Rosália bater carne cantando, apelidar as galinhas, conversar com os carneiros sujos, ensinar nome feio ao periquito, ralhar, batendo o pé, com o vento que, mexendo nas mangueiras, vinha tirar a roupa das cordas. Numa febril necessidade de experimentar a cegueira, certo de que podia (...) abrir os olhos de repente e ver as folhinhas 


\section{EM TESE}

Belo Horizonte, v. 6, p. I-253, ago. 2003

antigas na parede (...); ver as mangueiras, como se tivessem amadurecido os frutos subitamente; ver o cachorro dormindo nos velhos alguidares cheios de raízes e ervas feito animal fabuloso e os negros braços, ao sol, de Rosália a cozinheira, partindo lenha com seu indolente vagar. (Jurandir, 1947: 10)

Nesse retalho de memória, apreendido pela percepção visual do passado, o sujeito localiza Rosália entre as imagens que desfilam diante de um observador disposto a reencontrar sua própria identidade, através dos sentidos. Como a lente de uma máquina fotográfica, a memória amplia a imagem de Rosália para nela identificar o papel da mulher, no contexto da fazenda marajoara - um mundo à parte, privado, registrado a partir de uma condição social ocupada, na fazenda de Paricatuba.

A presença de Rosália nas reminiscências de Missunga dá conta do espaço ocupado pelas mulheres no interior da estrutura social criada no romance, estabelecendo uma ligação entre a memória individual e a memória social do sujeito que rememora. 0 mundo da Ilha do Marajó, é apreendido por Misssunga através das lembranças que combinam signos em movimento, em que os atos de "bater, cantar, conversar, ensinar, ralhar, mexer, tirar", evocados pela lembrança, adquirem vida, luz, cor, consistência, cheiro, sons e calor. Nesse instante, entram em ação as "antenas" de que fala Antônio Sérgio Bueno ao considerar que "através dos sentidos o corpo acolhe extensão, consistência, profundidade, temperatura, luz e cor das coisas e das paisagens do mundo" (Jurandir, 1947: 23).

A seqüência de imagens visuais, táteis, olfativas e auditivas - que se manifesta através da memória dos sentidos, dentro do romance Marajó - estabelece uma conexão entre passado e presente, realizando um percurso pelos espaços da memória que associa a infância à idéia de mobilidade, de ação e de movimento. Enquanto isso, o presente está ligado ao sentimento de fadiga e monotonia que envolve o adulto de volta para casa cujas "imagens do tédio e da infância misturando-se, (...) diante do desejo (...) que todos os desalentos se afundassem, todos os vagos ímpetos morressem para sempre (...) dentro de sua inércia. (...) por que viera da cidade para aquele torpor?" (Jurandir, 1947: 11)

Esse estado de consternação e desalento do sujeito diante da vida aproxima a rememoração, presente no romance Marajó, à obra de Pedro Nava, Baú de ossos, em que o sujeito da memória anuncia o sentimento de tristeza que envolve o tempo presente: 
[Q] uando caio no fundo da fossa, quando entro no deserto e sou despedaçado pelas bestas da desolação, quando fico triste ("mas triste de não ter jeito"), só quero reencontrar o menino que já fui. Assim, quantas e quantas vezes viajei, primeiro no espaço, depois no tempo, em minha busca, na de minha rua, na de meu sobrado. (Nava, 1999: 83)

Nos dois casos - sob a influência do descontentamento que envolve o tempo presente - o sujeito é compelido a fazer um recuo em busca de um fio qualquer que possa reconduzi-10 ao encontro de si mesmo. Em Baú de Ossos, esse recuo se dá através da "memória involuntária", que, segundo Deleuze, em Proust e os Signos, "é voltada para o futuro e não para o passado, (...) na busca da verdade (...) porque a verdade tem uma relação essencial com o tempo" (Deleuze, 1987: 4) Mas, ao contrário de Pedro Nava, Dalcídio Jurandir dispõe das experiências que concede, por empréstimo, aos personagens do romance. São essas experiências que irão dar suporte ao processo da memória dos vários personagens.

Que música Rosália cantava? que nome feio ensinava ao periquito? qual dos dois pés - o direito ou o esquerdo - Rosália batia, para ralhar com o vento? Como seriam as mangueiras - jovens, adultas, carregadas de frutos? Que cheiro teriam as mangas? Estariam verdes, maduras, amarelas? Com que palavras, a velha ama de Missunga ralharia com o vento?

Tantas perguntas ficarão sem respostas, por tratar-se de imagens apreendidas num momento dedicado à rememoração. Em sua leitura de Proust, diz Benjamin que "um acontecimento vivido é finito, ou pelo menos encerrado na esfera do vivido, ao passo que o acontecimento lembrado é sem limites, porque é apenas uma chave para tudo que veio antes ou depois" (Benjamin, 1994: 37). Os silêncios retidos no tempo fraturado das lembranças - sustentam a teoria de fragmentação e descontinuidade do processo rememorativo evidenciada por Walter Benjamin. Para esse teórico, a memória resulta do descontínuo de momentos vividos que ele considera como "encontro secreto que só se deixa fixar como imagem que relampeja irreversivelmente, no momento em que é reconhecido" (Benjamin, 1994: 201).

Nesse ponto, o sujeito do processo rememorativo encontra-se francamente voltado para o passado mais distante, mas reúne, em torno de si mesmo, dois passados distintos: o mais remoto - ligado à infância, e um outro, mais recente, conectado 


\section{EM TESE}

Belo Horizonte, v. 6, p. I-253, ago. 2003

com o referente social urbano. Mas é no presente da enunciação que a memória é acionada para re-fazer o percurso dessas duas fases precedentes, nas quais o sujeito irá imprimir as experiências adquiridas ao longo de sua existência individual, cujos acréscimos irão juntar-se às aquisições já existentes. No que se reporta a esse encontro entre dois passados, Walter Benjamin assinala a idéia de "um encontro secreto" entre o passado e o presente, ainda que o "passado só se deixe fixar, como imagem que relampeja irreversivelmente, no momento em que é reconhecido" (Benjamin, 1994: 235).

A realização desse encontro se efetiva por meio da articulação entre diferentes instâncias temporais, que corresponde à apropriação da reminiscência no momento em que ela relampeja no presente. Ainda com relação ao processo memorialístico, Walter Benjamin lembra, em suas teses, que a articulação do passado não significa conhecê-10 a partir de experiências precedentes. 0 filósofo alemão defende 0 caráter heterogêneo e fragmentário da rememoração, cujos fragmentos se justapõem interrompendo a cadeia linear dos acontecimentos.

As livres associações que o narrador faz mostram que o significante se antecipa ao referente mostrando que nessas memórias as experiências vividas em determinado espaço atribuem ao sujeito da memória uma autoridade que the permite agir como sujeito destas vivências. A mitificação do espaço da fazenda Paricatuba pelo narrador é responsável pela face dupla do sujeito dividido. Paricatuba é o cordão umbilical que transfigura a imagem da fazenda em centro.

No caso de Missunga, estamos diante de um sujeito que rememora, após ter sido deslocado de seu mundo familiar, ainda na infância, convivendo entre duas culturas: a cultura materna - no campo - e a cultura urbana, desconhecida, relacionada ao mundo da escrita, que obedece ao tempo do relógio e do calendário, impostos por outro sistema de marcação do tempo. Enquanto a infância era regida e orientada pela disposição das estrelas no céu, pelas estações das chuvas, pelo fluxo das marés cheia, preamar e vazante - sobre os grandes rios, caminho obrigatório para qualquer direção e distante do universo cronológico da máquina que mede o tempo, o passado recente era medido pelo tempo do relógio e do calendário. Não mais aquele objeto de decoração, esquecido na parede da casa da fazenda - como "as antigas folhinhas que 
seu pai deixava marcando um tempo morto nas paredes, entre as aranhas e as osgas tranqüilas e íntimas, como pessoas da família" (Jurandir, 1947: 10) -, mas um calendário que o obrigava a adequar-se à temporalidade, medida em horas e minutos. Essa identificação com o passado, vivido na fazenda Paricatuba, revela que o mundo, ordenado e regido por signos alheios ao seu mundo marajoara, permaneceria distante de sua compreensão e adaptação. 0 menino se transforma sem conseguir conciliar as experiências das duas fases.

Diante dessa trajetória do personagem, o próprio autor, como leitor de sua obra, considera que o romance Marajó é "a história do fazendeiro que fica girando entre o campo e a cidade, inútil a um e ao outro" (Jacob, 1996: 31). Essa visão coincide com a posição do narrador cuja impressão é mais ou menos a mesma: "Missunga preso ao seu mundo, desovando na solidão o seu pensamento desasado e miúdo. Rico e inútil, sem saber coisíssima; não dava para nada. Para nada". (Jurandir, 1947: 52) 


\section{EM TESE}

Belo Horizonte, v. 6, p. I-253, ago. 2003

ABSTRACT :

This essay focuses on the process of remembering by means of the articulation between different temporal instances, which corresponds to the appropriation of the reminiscence in the moment it flashes in the present. The associations are brought by the memory process and involve several spatial and temporal dimensions.

KEY WORDS: narrative, space, time, memory.

BUENo, Antônio Sérgio. Vísceras da memória. Belo Horizonte: Ed. UFMG, 1997.

BENJAMIN, Walter. Magia e técnica, arte e política. Trad. Sérgio Paulo Rouanet. Prefácio Jeanne Marie Gagnebin. 7. ed. São Paulo: Brasiliense, 1994. (Obras escolhidas, v. I).

DELEUZE, Gilles. Proust e os signos. Trad. Antonio Carlos Piquet e Roberto Machado. Rio de Janeiro: Forense Universitária, 1987.

JACOB, Maria Célia (Org.). Revista Asas da Palavra, Belém: Unama, n.4, 1996.

JURANDIR, Dalcídio. Marajó. Rio de Janeiro: José 01 ímpio, 1947.

NAVA, Pedro. Baú de Ossos. São Paulo: Atelier Editorial,1999. 